\title{
INTEGRAÇÃO DAS PRÁTICAS SOCIAIS A PARTIR DAS NORMAS ISO 9000, 14000 E 16000
}

\author{
Márcia França Ribeiro Fernandes dos Santos
}

José Antonio Assunção Peixoto

Leydervan de Souza Xavier

\section{RESUMO}

O objetivo do artigo é elaborar uma proposta de integração das práticas sociais normalizadas pelas normas das séries ISO 9000, 14000 e 16000, entendidas como objetos técnicos, fundamentada em um referencial teórico extraído das obras: "A Natureza do Espaço", de Milton Santos, "A Constituição da Sociedade", de Anthony Giddens, e "O Conceito de Tecnologia", de Álvaro Vieira Pinto. A metodologia consiste em uma pesquisa exploratória, que busca os elementos conceituais nas referidas obras dos autores citados que se enquadrem no texto das normas ISO 9000, 14000 e 16000, auxiliando assim seu entendimento. 0 estudo indica que as normas devem ser analisadas dentro de um contexto envolvendo o ator, a ação, o espaço e o tempo. Entretanto, há que se modificar a visão das organizações que, principalmente com relação à implantação das normas ISO, priorizam a ação com o objetivo de padronizá-la.

Palavras-chave: Práticas sociais. Normas ISO. Milton Santos. Anthony Giddens. Álvaro Vieira Pinto.

\begin{abstract}
The objective of the article is to draw up a proposal for the integration of social practices normalized by the standards of the ISO 9000 series, 14000 and 16000, understood as technical objects, based on a theoretical reference extracted from the work: "The Nature of Space", Milton Santos, "The Constitution of the Society," by Anthony Giddens, and "The Concept of Technology", Álvaro Vieira Pinto. The methodology consists of a exploratory research, which seeks conceptual elements in those works of authors cited falling in the text of ISO 9000, 14000 and 16000, thus helping their understanding. The study indicates that the standards must be examined in context involving the actor, action, space and time. However, we must change if the vision of organisations, particularly with respect to the deployment of ISO, prioritize the action with the objective of stardardizing it.
\end{abstract}

Keywords: Social practices. ISO. Milton Santos. Anthony Giddens. Álvaro Vieira Pinto. 


\section{INTRODUÇÃO}

Desde a antiguidade, o homem sempre buscou a solução para seus questionamentos a partir da reflexão de suas interações com a natureza. Segundo SANTOS (2006), a técnica materializa esta relação entre os indivíduos e o meio.

No entanto, depois da Segunda Guerra Mundial, o relacionamento entre as nações começou a sofrer alterações, especialmente no que se refere às relações comerciais. Tais modificações se acentuaram na segunda metade do século XX, devido ao fenômeno da globalização em sua fase neoliberal.

Com o advento da chamada economia do conhecimento, houve uma intensificação dos fluxos de capitais e serviços. As regras de comércio se tornaram mais amplas, pois passaram a englobar não apenas bens manufaturados, mas também serviços e propriedade intelectual.

Neste cenário marcado por mudanças, a figura da tecnologia ganhou uma importância destacada e o homem passou a maravilhar-se com as técnicas, fruto de sua própria criação.

Assim, o fenômeno estudado pelo homem para sanar os seus problemas, que antes era entendido como comportamento da natureza, passou a ser compreendido como o comportamento dos outros homens, pois os indivíduos passaram a ter acesso aos fenômenos do mundo físico através das relações sociais (VIEIRA PINTO, 2005).

Consequentemente, a essência da técnica agora está fundamentada na maneira pela qual os homens organizam as relações sociais de produção, que estão ordenadas no tempo e no espaço.

Dentro deste contexto, a finalidade deste estudo é elaborar uma proposta de integração das práticas sociais normalizadas pelas normas das séries ISO 9000, 14000 e 16000, entendidas como objetos técnicos, fundamentada em um referencial teórico extraído das obras: "A Natureza do Espaço", de Milton Santos, "A Constituição da Sociedade", de Anthony Giddens, e "O Conceito de Tecnologia", de Álvaro Vieira Pinto.

\section{FUNDAMENTOS TEÓRICOS DOS AUTORES}

As normas são produto da cultura humana e se destinam a intervir nas práticas das organizações voltadas para alguma atividade de trabalho. Nesta intervenção a repetição e a reprodução segundo um sistema de valores e de métodos é de importância capital.

Para uma visão crítica de qualquer norma técnica ou conjunto de regras de qualquer natureza é necessária a sua contextualização, no tempo e no espaço. Assim, são elementos relevantes para a análise e representação: o ator, a ação, o espaço e o tempo relacionados ao sistema de interesse.

As ações que são objeto de normalização, em geral, podem ser consideradas ações técnicas. Mas como defini-las em sentido geral? Segundo Santos (2006 p.29) "as técnicas são um conjunto de meios instrumentais e sociais, com os quais o homem realiza sua vida, produz e, ao mesmo tempo, cria espaço".

As técnicas ocorrem no tempo e no espaço. 0 conceito de espaço, apropriado da Geografia, é de "um sistema de objetos e de ações" (SANTOS, 2006). Os objetos podem ser produzidos pela ação humana (objeto técnico) ou pela natureza (objeto natural). Quando a ação humana não se manifesta pode-se pensar no espaço como uma paisagem natural. As ações e os objetos 
humanos interagem com os fenômenos e objetos naturais criando novos espaços, segundo a definição adotada.

As técnicas (ações) e os objetos técnicos, portanto, criam novo espaço. As ações têm duração, assim como as interações com os objetos e, assim, o espaço, como foi definido, só pode ser analisado acoplado ao tempo. As ações podem ser consideradas cadeias de eventos, em que tempo e espaço se fundem e materializam. As ações ocorrem no espaço e no tempo, assim como se apresentam seus significados para os que com elas interagem.

Neste sentido, as normas podem ser descritas como objetos técnicos destinados à intervenção nos fenômenos naturais e sociais com finalidade de atender necessidades aceitas. Como objetos construídos carregam um conjunto de significados, de intencionalidades e de valores, inclusive ideológicos, que se manifestam no tempo e no espaço no momento em que ocorrem as ações. Estes objetos criam novos significados para aqueles que se apropriarão deles, influenciando suas ações que se concretizarão, de alguma forma (técnica ou não) no espaço e no tempo.

O espaço, porém, como definido acima, não está confinado ou delimitado, ao contrário, é um contínuo. Basta que a existência de objetos ou ações de qualquer origem se faça presente. Deste modo, objetos ou ações que foram produzidos no tempo passado ou em regiões remotas podem alterar o espaço de interesse neste momento.

Ações atuais, oriundas de outras regiões do planeta (externalidades), assim como objetos lá produzidos com determinada intencionalidade e impregnados dos significados locais transformam o espaço em que se apresentam, quando se apresentam. Os objetos que se encontram no espaço, mas cujos significados se perderam no desenrolar do tempo, podem ser considerados rugosidades (SANTOS, 2006). Edificações, monumentos ou quaisquer objetos técnicos ou naturais podem ser rugosidades do espaço em que se atua. A obsolescência funcional dos objetos (ferramentas, códigos de procedimentos e leis) faz com que não se interaja mais com eles e que percam o significado para os atores em suas ações posteriores.

As organizações são construções da sociedade humana e, à luz das considerações anteriores, são espaço-tempo, porque são sistemas de ações e de objetos. Como espaço-tempo as organizações se transformam com os objetos e as ações e a dinâmica de vida dos significados produzidos pelos atores humanos.

Os sistemas de produção muitas vezes são usados para caracterizar o estágio de desenvolvimento tecnológico de um sistema social, ou, mais especificamente, de uma organização dentro dele. A capacidade de produzir e de gerir a produção de acordo com preceitos normalizados também é utilizada como medida deste desenvolvimento tecnológico. Mas, no espaço-tempo das organizações, o que é tecnologia?

Adotando-se, como embasamento teórico, a abordagem filosófica de Vieira Pinto (2005), são quatro as concepções de "tecnologia" que se podem distinguir, considerando-se que o termo é usado por pessoas das mais variadas áreas do conhecimento: etimologicamente a "tecnologia" tem de ser a teoria, a ciência, o estudo, a discussão da técnica. Neste significado, estão abrangidas as artes, as habilidades do fazer, as profissões e qualquer forma de se produzir algo. Trata-se, assim, do "logos da técnica".

No segundo significado "tecnologia" equivale simplesmente à técnica. Este é o uso popular mais encontrado, desprovido de uma precisão de linguagem. 0 terceiro conceito guarda grande afinidade com o segundo, entendendo-se "tecnologia" como o conjunto de todas as 
técnicas que detém uma coletividade, em dado momento de sua história. 0 quarto sentido "tecnologia" se refere à ideologia da técnica. A se considerar o "desenvolvimento tecnológico" de uma empresa, de um país ou de um povo, emprega-se a terceira concepção orientada pela quarta, com claro sentido ideológico.

Propõe, ainda, Vieira Pinto (2005) que o homem é um ser técnico. Ao lidar com sua contradição existencial de enfrentar e dominar a natureza, produzindo algo que lhe é necessário, o homem engendra o ato técnico; mas este ato que transforma a paisagem da natureza, transforma também o próprio homem, no contexto das relações sociais em que a produção é realizada e realimenta o processo, com a concepção e a substituição das ações por outras mais eficazes, refletidas nas relações com os outros homens. Esta relação entre o ser técnico e o ato técnico na sua essência, humaniza o homem através do fazer no meio social. A linguagem, neste sentido, pode ser tomada como a técnica imemorial de todas as técnicas.

Segundo Santos (2006) é necessário um sistema de referência elaborado de modo a compreender a técnica. Enquadrando-se, então, os sistemas de gestão e de produção como tecnologia e esta como ação humana, estruturada por princípios que são gerados e mantidos pelas relações humanas nas organizações da sociedade, tem-se uma base de referência teórica para analisar o movimento de integração de sistemas e normas de gestão.

Com relação à ação humana, Giddens (2003) afirma, à semelhança da cognição, que a mesma ocorre como um fluxo contínuo de conduta - a ação intencional não é composta de uma série de intenções, razões e motivos isolados. De acordo com o autor (2003 p.3) "A monitoração reflexiva da ação depende da racionalização, entendida aqui mais como um processo do que como um estado, e como inerentemente envolvida na competência dos agentes".

Dentro do contexto de racionalização da ação, Giddens (2003 p. 3) aponta que "as normas se apresentam como fronteiras factuais na vida social, para as quais são possíveis várias atitudes manipulatórias". Como exemplo de tais atitudes, o autor se baseia na observação de que as razões que os atores disponibilizam discursivamente para o que fazem podem divergir da racionalização da ação efetivamente envolvida no fluxo de conduta desses atores.

Por meio da racionalização da ação, Giddens (2003) entende que os atores mantêm um nível de "entendimento teórico" das bases de sua atividade. Porém, possuir tal entendimento não deve estar restrito à apresentação discursiva de razões para determinados itens de conduta ou mesmo à capacidade do ator de relatar tais razões discursivamente. 0 principal critério de competência aplicado na conduta cotidiana, ou seja, o que agentes competentes esperam de outros, se fundamenta no fato de que os atores estejam habitualmente aptos a explicar a maior parte do que fazem quando indagados.

Giddens (2003 p.5) destaca que "embora atores competentes possam quase sempre informar discursivamente sobre suas intenções ao - e razões para - atuar do modo que atuam, podem não fazer necessariamente o mesmo no tocante a seus motivos".

Dentro deste referencial teórico, Giddens conceitua a principal distinção entre a consciência discursiva da consciência prática. A primeira refere-se ao que pode ser dito e a segunda refere-se o que, de modo característico, é simplesmente feito.

Os agentes humanos sabem o que estão fazendo no nível da consciência discursiva, sob alguma forma de descrição. No entanto, o que eles fazem pode lhes ser completamente desconhecido sob outras descrições, e talvez os referidos atores conheçam muito pouco a 
respeito das consequências das atividades que estão desempenhando.

\section{PROPOSTA DE INTEGRAÇÃO DAS PRÁTICAS SOCIAIS PELAS NORMAS ISO}

Para o estudo em questão, definir-se-á norma como um conjunto de regras que se destina a intervir no ambiente, com o objetivo de sistematizar os eventos, garantindo-lhes a repetição e a reprodução e envolvendo quatro parâmetros relevantes: o ator, a ação, o espaço e o tempo.

Santos (2006) desenvolveu uma abordagem espaço-tempo para estudar a geografia, cujo objeto é o espaço, que será apropriada na integração dos sistemas de gestão tendo em vista que este referencial teórico é passível de aplicação em qualquer tema. Para o autor a técnica, que é a principal forma de relação entre o homem e o meio, se materializa no espaço e no tempo.

Vieira Pinto (2005) enfatiza também a importância de contextualizar a técnica, no caso em estudo o objeto técnico é a norma, dentro de um âmbito social definido, ou seja, uma ação realizada por um ator situado no tempo e no espaço.

Dentro do contexto das normas, cada uma individualmente não explica nada sozinha, ou seja, é necessário um sistema de referências elaborado (baseado no tempo e no espaço) de modo a entendê-las; ou seja, cada norma tem um histórico e foi criada para sanar um problema específico do homem para com o meio.

Como exemplo, cabe citar que a série ISO 9000 sofreu alterações no decorrer dos anos de modo a melhorar seu escopo - ex: inserção do mecanismo de Plan-Do-Check-Act (PDCA). Esta melhoria levou a resultados favoráveis para as organizações, levando o PDCA a ser incorporado nas normas da série ISO 14000 e ISO 16000.

Conforme destacado acima, as normas, em especial as de gestão, foram idealizadas para sistematizar os eventos (onde o conjunto de eventos irá formar a ação) e garantir que haja sua repetição e reprodução ao longo do tempo e do espaço, ou seja, seu objetivo é que a técnica se torne universal. Neste contexto, é possível vislumbrar a norma como um objeto técnico que busca a universalidade.

Tal objetivo é atingido quando há a ordenação dos espaços e a padronização de modelos. Como exemplificação da padronização das normas, cita-se o exemplo das construções de shopping centers e aeroportos, que são iguais na maioria das partes do mundo. Neste caso, do ponto de vista do objeto técnico em si, houve a padronização dos designs e funcionalidades de tais objetos através da adoção de normas de construção.

No entanto, do ponto de vista da técnica, é mais difícil obter a padronização tanto das técnicas de produção como das técnicas de enquadramento, uma vez que a ação técnica pode ser a mesma, mas o ator, o espaço e o tempo são diferentes.

Muitos poderiam pensar ser mais fácil padronizar as técnicas de produção, ou seja, aquelas referentes à transformação da matéria-prima em produto. Porém, isto não é verdadeiro e para facilitar este entendimento será feita uma comparação entre uma fábrica de tênis na China e no Brasil, partindo da premissa de que ambos seguem o mesmo conjunto de normas. A norma, ou a técnica, para fazer o tênis pode ser a mesma no Brasil e na China, mas o objeto, a história (tempo) e os atores não os são.

Os atores são distintos porque na fábrica no Brasil trabalham brasileiros, com um 
determinado nível de instrução, com expectativas, com um salário diferente do trabalhador chinês que pode inclusive trabalhar sobre regime de escravidão. 0 tênis (objeto técnico) fabricado no Brasil será diferente daquele produzido na China uma vez que o formato, tamanho e as quantidades que serão produzidas do mesmo deverão estar de acordo com o mercado para os quais os tênis serão exportados.

Neste contexto, as normas da série ISO 9000 serão utilizadas para ajustar os parâmetros da produção e as especificações do produto de acordo com o contexto político, social, econômico, ambiental dentre outros de cada um dos países de maneira distinta.

No caso das chamadas técnicas de enquadramento, aquelas referentes à transformação da informação em representação, o grau de dificuldade de padronização é maior. Para exemplificar, utilizar-se-á a norma da série ISO 16000 relativa à responsabilidade social.

De acordo com tal norma, o conceito de responsabilidade social está associado à questão do desenvolvimento sustentável que se desdobra em três dimensões: econômica, ambiental e social. A norma prega que o seu uso "não elimina, engloba ou substitui o uso das normas da série ABNT NBR ISO 9000 ou ABNT NBR ISO 14000, cabendo às organizações a decisão de aplicá-la em conjunto ou separado, dependendo das suas necessidades estratégicas" (ABNT NBR ISO 16001, 2004).

Em tal norma de gestão, o envolvimento e a integração entre as normas da série ISO 9000 e ISO 14000 destacam a importância das técnicas das relações entre os homens e das técnicas de organização do espaço que atinge todas as dimensões acima elencadas. Cabe ressaltar ainda que a norma deixa em aberto como esta integração, que pode ser feita ou não, deve ser conduzida de acordo com cada organização.

Desta forma, cada organização tem um certo grau de autonomia para ajustar seus sistemas de gestão de responsabilidade social de acordo com seu planejamento estratégico, ressaltando aquelas práticas que julgar relevante para a sobrevivência de seu negócio.

Além disso, é possível observar que as normas da série ISO, de uma forma geral, têm sido utilizadas como uma ideologização da técnica, impondo uma lógica perversa de dominação, tanto econômica como cultura, por parte das potências hegemônicas.

Do ponto de vista econômico, a norma ABNT NBR ISO 14001 (2004) diz na sua introdução que "não se pretende que estas Normas, tais como outras normas, sejam utilizadas para criar barreiras comerciais não-tarifárias, nem para ampliar ou alterar as obrigações legais de uma organização".

Apesar da norma da série ISO 16000 discriminar em seu objetivo uma idéia semelhante, o que ocorre na prática é que as normas, especialmente as de gestão, se converteram em uma importante ferramenta de dominação econômica no contexto geral dos sistemas produtivos. Os países avançados, ancorados no domínio das tecnologias da informação e comunicação, se apropriaram das normas como uma forma de exercer controle sobre aqueles ditos atrasados.

Com o fenômeno da globalização, as nações precisaram expandir o mercado para fora de suas fronteiras; ao mesmo tempo desejavam guardar o seu próprio mercado, especialmente no que diz respeito às áreas chaves, tais como, segurança, telecomunicações dentre outras, que ficaram sob o olhar atento do Estado nos países avançados, ainda que o discurso neoliberal pregado fosse de um Estado não intervencionista na economia. 
Desta forma, os países hegemônicos impõem aqueles menos favorecidos as barreiras tarifárias e as não tarifárias (as chamadas barreiras técnicas), bem como o uso das normas da série ISO.

O uso das normas é "voluntário", mas para que se possa comercializar em âmbito mundial, especialmente com os países desenvolvidos, é necessário que os países subdesenvolvidos a adotem sob pena de serem excluídos do comércio mundial.

Considerando o ponto de vista cultural, a norma, vista como técnica, vem sendo a responsável pela homogeneização/universalização da cultura imposta pelos países dominantes. Tal dominação ocorre em duas direções. Na primeira vertente, os países desenvolvidos investem na valorização da figura do chamado "técnico" dentro da cultura dos países subdesenvolvidos.

Cabe ressaltar que tal técnico fica no nível da consciência prática, ou seja, de um modo geral é capaz de explicar o que faz, mas não é capaz de explicar a si mesmo por que o faz.

Além disso, em uma segunda vertente, os países atrasados não têm um projeto de nação, isto é, um conjunto de valores acordados com a sociedade. Neste contexto, são mais facilmente dominados, pois acreditam que, como não tem tecnologia endógena - isto não é verdade, aceitam importar a tecnologia ofertada pelos países hegemônicos, não levando em consideração as reais necessidades da nação. Com isto, há uma real perda da soberania nacional. Além disso, a tecnologia disponibilizada, vista pelos países atrasados como uma dádiva que será capaz de lhes tirar do atraso científico em que estão mergulhados, já está obsoleta.

Agora, salienta-se a questão da norma como um objeto técnico criado com a finalidade de intervir na ação humana, executada em um espaço-tempo, de modo a superar um problema do homem como o meio. No caso das normas da série ISO 9000, 14000 e 16000 as mesmas evoluíram de acordo com as necessidades identificadas pelo atores envolvidos em seus ambientes organizacionais, conforme abaixo elencadas:

- $\quad$ 1a geração das normas - ISO 9000 - ênfase na qualidade de produtos e processos;

- $\quad$ 2a geração das normas - ISO 14000 - ênfase na questão ambiental; e

- $\quad 3^{\text {a }}$ geração das normas - ISO 16000 - ênfase na questão da responsabilidade social.

Desta forma, o processo dialético da integração das normas acontece da seguinte forma: as normas/regras são seguidas sem questionamento; só sendo questionadas quando não dão conta de explicar a realidade. Consequentemente, as normas evoluem porque a sociedade (na dimensão de espaço-tempo), os atores envolvidos e a percepção dos problemas junto ao meio mudam, alterando assim o modo de reprodução das práticas sociais.

Neste sentido, a norma pode ser definida como um processo intersubjetivo e intencional com a finalidade de seguir requisitos objetivos escritos formalmente no escopo da mesma. Mas, por outro lado, também apresenta um aspecto subjetivo que se refere aos atores, espaço e tempo a que está sujeita as práticas sociais acordadas. Desta forma, é possível observar na norma uma dualidade entre suas características de cunho objetivo e subjetivo.

\section{CONCLUSÕES}

Elaborar uma proposta de integração das práticas sociais no âmbito das normas da série ISSO 9000, 14000 e 16000 foi um desafio complexo porque envolveu a junção de conceitos 
elencados pelos autores Milton Santos, Anthony Giddens e Álvaro Vieira Pinto. Cabe destacar a existência de alguns pontos em comum entre a abordagem dos três autores.

Como exemplo foi observado que a ontologia de tempo e espaço está presente em todas as obras bem como a interação entre, o que Milton Santos chamou, de sistema de objetos e sistema de ações. Além disso, a epistemologia da técnica está fundamentada na maneira com que os homens organizam as relações sociais de produção, especialmente no contexto das normas acima citadas.

Pontos específicos de cada autor foram utilizados para a construção da proposta em questão. De Milton Santos foi utilizado essencialmente a abordagem espaço e tempo e a técnica como relação entre o homem e o meio; no trabalho de Anthony Giddens extraíram-se os conceitos de consciência prática e discursiva, intencionalidade e dualidade; e nos estudos de Álvaro Vieira Pinto foi realçada a questão da ideologização da técnica, notoriamente o aspecto de dominação por trás da adoção das normas.

Por fim, conclui-se que as normas devem ser analisadas dentro de um contexto envolvendo o ator, a ação, o espaço e o tempo. Entretanto, há que se modificar a visão das organizações que, principalmente com relação à implantação das normas ISO, priorizam a ação com o objetivo de padronizá-la. Porém, a ação não deve ser estudada suspensa no espaço, sem causa nem relações temporais e principalmente desvinculada do agente envolvido, pois são estes três aspectos que perpassam a ação, a modificando nas diferentes relações sociais.

\section{BIBLIOGRAFÍA}

ABNT NBR ISO 14001 (2004): Sistemas da Gestão Ambiental - Requisitos com orientações para uso. Associação Brasileira de Normas Técnicas. ABNT 2004.

ABNT NBR ISO 16001 (2004): Responsabilidade Social - Sistema da Gestão - Requisitos. Associação Brasileira de Normas Técnicas. ABNT 2004.

GIDDENS, A. (2003): A Constituição da Sociedade. São Paulo: Editora Martins Fontes.

VIEIRA PINTO, A. (2005): O Conceito de Tecnologia. Volume I. Rio de Janeiro: Editora Contraponto.

SANTOS, M. (2006): A Natureza do Espaço. 4aa edição. São Paulo: Editora da Universidade de São Paulo. 